\title{
Study on the Synthetic Ammonia with Methanol Purge Gas of Huangling
}

\author{
Zongyi Yang, Meili Du, Chen Chen, Xin Yi and Doudou Wang \\ College of Chemistry and Chemical Engineering, Xi' an University of Science and Technology
}

\begin{abstract}
Methanol purge gas produced in the side reaction in the methanol production were the inert gas including $\mathrm{H}_{2}, \mathrm{CO}$, $\mathrm{H}_{2} \mathrm{O}, \mathrm{CH}_{4}$ and others, which was used to produce synthetic ammonia as an important part in circular economy industrial chain of Huangling coal chemical industry. In this paper, the process and the optimal processing conditions to produce synthetic ammonia with $\mathrm{N}_{2}$ in the air separation and $\mathrm{H}_{2}$ in methanol purge gas as raw material were discussed. It was shown that the research results had a significant enhancing effect on the realization of energy conservation and emission reduction, environment protection, the green development patterns to change waste into valuable, and the sustainable development of coal chemical industry for Huangling Coal Chemical Industry Group.
\end{abstract}

Keywords-methanol purge gas; pressure-swing adsorption; synthetic ammonia; raw gas compression

\section{Significance OF Producing Synthetic Ammonia With Huangling Methanol Purge Gas}

The production equipment for annual output of 2 million tons of coke and 300,000 tons of coke gas methanol has been established by Huangling Coal Chemical Industry Group. Methanol production plant generated a large amount of methanol purge gas $\left(36412 \sim 40053 \mathrm{Nm}^{3} / \mathrm{h}\right.$, average $38232 \mathrm{Nm}^{3} / \mathrm{h}$ ) which had a high concentration of hydrogen $(77.05 \%)$. It would not only cause serious environmental pollution, but also bring a great waste of resources if methanol purge gas could not be used properly. Methanol purge gas which was generated by the equipment was sufficient to produce synthetic ammonia with an annual output of 100,000 tons. It was consistent with the China's industry policy and was the best way to maximize the benefits of that kind of resources that $\mathrm{H}_{2}$ in methanol purge gas and $\mathrm{N}_{2}$ in air separation plant were used to produce synthetic ammonia[1]. The way to use methanol purge gas had a low investment cost, low energy consumption, significant economic and social with great significance benefits to the sustainable development of enterprises.

\section{SYNTHETIC AMMONIA PREPARATION TECHNOLOGIES With Huangling Methanol Purge GaS}

\section{A. Components Composition of Methanol Purge Gas}

Huangling methanol purge gas contained kinds of gas components such as $\mathrm{H}_{2}, \mathrm{~N}_{2}, \mathrm{CH}_{4}, \mathrm{CO}, \mathrm{CO}_{2}, \mathrm{H}_{2} \mathrm{O}, \mathrm{H}_{3} \mathrm{OH}$, and others. The order of content of main gases in methanol purge gas from the larger one to the small one were $\mathrm{H}_{2}, \mathrm{~N}_{2}, \mathrm{CO}, \mathrm{CO}_{2}$, $\mathrm{CH}_{4}, \mathrm{H}_{2} \mathrm{O}$ and $\mathrm{CH}_{3} \mathrm{OH}$, with $77.05 \%, 9.56 \%, 6.85 \%, 3.65 \%$, $2.70 \%, 0.12 \%$ and $0.07 \%$ respectively, from which it was shown that the content of $\mathrm{CO}_{2}$ and $\mathrm{CH}_{4}$ were similar, and that of $\mathrm{H}_{2} \mathrm{O}$ and $\mathrm{CH}_{3} \mathrm{OH}$ were little.

\section{B. Synthetic Ammonia Process with Methanol Purge Gas}

First, the methanol purge gas flowed through a pressure swing adsorption apparatus to obtain hydrogen with more than $99.9 \%$ purity. Then high purity hydrogen and nitrogen in air separation plants were compressed and introduced into the mixer to blend well. Secondly, the mixed gas after mixing get into the ammonia plant by being pressurized, and refrigeration cooling energy for the ammonia plant was provided by ammonia refrigeration system. Finally, the ammonia products were put into liquid ammonia storage tank. The purge gas in liquid ammonia tank was recycled to produce ammonia, which was sent to thermoelectric plant as raw materials to desulfurize and reduce nitrogen.

\section{1) Feed gas compressor}

Piston compressor was driven by steam turbine. The nitrogen, produced in ASU and then increased pressure by screw compressor, was impressed and introduced into methanation units, and mixed gas after methanation and then pressurized was feed into synthesis devices.

\section{2) Ammonia synthesis unit}

The mixed hydrogen and nitrogenthrough heat exchanger was introduced into the synthesis tower, and then was produced into synthesis ammonia with catalyst at a certain temperature and pressure conditions. After air cooling and ammonia cooling, ammonia in the mixed gas was condensed into liquid ammonia and separated, and sent to ammonia storage.

\section{3) Recycle gas compressor}

Hydrogen and nitrogen after ammonia separation in synthesis system returned to the systemto continue react by the cycle gas centrifugal compressor, the task of which was to provide circulated process gas for the ammonia production systems, and to increase the rate of ammonia synthesis.

\section{4) Ammonia compressor}

The ammonia gas cooled by liquid ammonia flowed through synthesizer, and then was compressed by the screw compressors into cooling liquid ammonia, which was sentinto synthesizerto cool gas circularly.

\section{5) Storage and filling of liquid ammonia}

Commodity liquid ammonia was stored by two 2000 cubic meters of liquid ammonia tanks and liquid ammonia was sold by two automated filling systems. 


\section{6) Membrane hydrogen extraction unit}

Hydrogen gas from the discharge air was purified through the membrane mention hydrogen device, which was used as feed gas of synthesis ammonia by pressure swing adsorption, production and recovery of ammonia was sent to the thermoelectric plant as a raw material of desulfurization out of stock. Under the effect of certain pressure, when the synthesis discharge air flowed through the polymer membrane, $\mathrm{H} 2$ could quickly penetrate through the membranes, and $\mathrm{N} 2, \mathrm{CH} 4$ and other gases would be much slower. In the low-pressure side of the membrane, $\mathrm{H} 2$ concentration increased rapidly, and the majority of N2, CH4 were stagnant in the high-pressure side of the membrane, so as to achieve the purpose of separation of hydrogen mention.

\section{Main Technology of Methanol Purge Gas DEFLATION SYNTHETIC AMMONIA}

\section{A. Turbine Driven Reciprocating Compressors}

\section{1) The selection of compressor}

The requirements on feed gas compressor during synthetic ammonia production wereas follows: (1)The change of gas volume and pressure should be regulatory. It was required to be convenient for compressor installation, inspection and maintenance in the production process to detect and operate easily. (2) It was required the project should have low-investment and high-efficiency equipment, small construction coverings and workshop foundation, low-energy consumption and long-periodic operation, strong standardization and interoperability of easy-damaged parts. (3)It was required to set security early warning and exceeded facilities to prevention of pressure, temperature to ensure tightness (static seals, dynamic seals) to prevent gas leakage avoiding the explosion during gas combustion. It was needed to set up automatic test and recording equipment for pressure, temperature, vibration, flowing, displacement of the movable member. (4) Since the steam turbine driven generator would change heat into electricity, and electrical energy would be transferred into kinetic energy by motor driving compressor, causing losses and waste of energy, reciprocating compressors was driven by steam turbine to reduce energy losses and increase energy efficiency[3].

\section{2) Key techniques}

\section{a) Vibration elimination}

High-speed coupling, low coupling of coil spring type and flywheel were set up in the transmission chain consisting of a steam turbine, gear unit and the compressor. Load of reciprocating compressor was uneven, while the steam turbine required loads must be uniform. In order to meet the vibration requirements of turbine in the drive train consisting of steam turbine, high-speed coupling, the low coupling of coil spring type and flywheel were set up in gear unit and the compressor. First, the pulse load of the compressor was even eliminated by the flywheel, and then no-elimination impact load, axial movement were isolated out of reducer through special helical spring low speed coupling.

\section{b) High-speed coupling and clutch operation}

Setting high-speed gear sleeve with a clutch function coupling was set up between the turbine and gear. If there was an emergency stop, such as the compressor in a failed state, system could be equally stop as quickly as the motor drive, the clutch could disengage the reducer, compressor and turbine after the system would shut down quickly, which the turbine would return the back into the slow cranking state to ensure uniform cooling of its various parts. At the same time, high-speed gear sleeve couplings also had axial thermal displacement compensation function between turbine and decelerator.

\section{c) Compressor features}

(1)The energy consumption of steam turbine driven reciprocating compressor would be more $30 \%$ than the energy-efficient electrically driven reciprocating compressors, and the cost of ammonia per ton would be lower than the same scale synthetic ammonia manufacturers about $\$ 300$.

(2)High-speed coupling, the coil spring type low coupling and flywheel were set up in the transmission chain consisting of turbine, reducer and compressor.

(3)High-speed gear sleeve coupling was set up between the turbine and gear. When the reciprocating compressor open and park frequently, steam could enter into a slow cranking state.

\section{B. Hydrogen Extraction by PSA Technology}

1) Process selection of hydrogen extraction from methanol purge gas

There were two main technologies to extract hydrogen from methanol purge gas that PSA technology [4] and membrane separation technology[5].Because the membrane separation technology were not suitable for this unit process conditions and had high investment costs, PSA technology was adopted to purify the methanol purge gas.

\section{2) PSA technologycharacteristics}

(1)PSA principle: $\mathrm{H}_{2}$ is the main component of methanol purge gas, with the rest made up of $\mathrm{CO}, \mathrm{O}_{2}, \mathrm{CO}_{2}, \mathrm{CH}_{4}, \mathrm{~N}_{2}$ and hydrocarbons of $\mathrm{C}_{2} \sim \mathrm{C}_{4}$. The purpose to separate $\mathrm{H}_{2}$ and other impurities was achieved with adsorbent selective absorption on the various components of the gas.

(2)Saving energy: During the production of hydrogen, the gas for regeneration could be utilized circularly, and analytical gas returned back to the gas system or may be used as methanol raw material gas without waste.

(3)The process high-purity hydrogen could be separated from methanol purge gas with this technology, which was simple, low-investment, and low-cost with high degree of automation.

\section{Methanation Technology}

Selection of Methanation process was that a small amount of $\mathrm{CO}, \mathrm{CO}_{2}(\leq 0.2 \%)$ in the $\mathrm{H}_{2}$ after hydrogen extracting with PSA and $\mathrm{O}_{2}(\leq 0.1 \%)$ among $\mathrm{N}_{2}$ in air separation plant, which was harmful to the ammonia synthesis catalyst, must be removed. There were many methods to deal with the difficulty, 
such as copper acetate liquid ammonia cleaning method (chemical method), the depth of the low variant methanation (chemical method), low temperature liquid nitrogen washing method (physical method), double-A (methanol, methanation) methanation process (chemical method) and alcohol alkylation method.

The more advanced low pressure (3.1MPa) methanation process[6]was adopted to remove harmful ingredients in the feed gas, making it less than 10ppm, which had a wide range of applications in small domestic fertilizer plant in recent years.

The technology principle:

$$
\begin{aligned}
& \mathrm{CO}+3 \mathrm{H}_{2}=\mathrm{CH}_{4}+\mathrm{H}_{2} \mathrm{O}+206.16 \mathrm{~kJ} \\
& \mathrm{CO}_{2}+4 \mathrm{H}_{2}=\mathrm{CH}_{4}+\mathrm{H}_{2} \mathrm{O}+165.08 \mathrm{~kJ}
\end{aligned}
$$

The methanation reaction was a strong oxidation reaction, and there was water produced by the reaction between $\mathrm{H}_{2}$ and $\mathrm{O}_{2}$ on the condition of the presence of $\mathrm{O}_{2}$.

The technology characteristics were that it had simple equipment, easy operation, low pressure, stable system, convenient start-up and shut-down, high-degree of automation, low investment and operating cost, and other advantages.

\section{The Recovery and Utilization Technology of Synthetic Ammonia Purge Gas}

There were two parts of purge gas in the production of synthetic ammonia that could be recycled. 1, there was purge gas in synthetic equipment about $1300 \mathrm{Nm}^{3} / \mathrm{h}$, including $62.6 \% \mathrm{H}_{2}, 5.2 \% \mathrm{NH}_{3}$ which could be recycled. 2, there was purge gas about $1988 \mathrm{Nm}^{3} / \mathrm{h}$ in two liquid ammonia tank of $2000 \mathrm{~m}^{3}$, including $48.4 \% \mathrm{NH}_{3}$ which was the effective components to be recycled. Combined with the company's actual conditions, there were two methods. The first was that $\mathrm{H}_{2}$ was extracted from purge gas in synthetic tower by membrane separation technology. The $\mathrm{NH}_{3}$ was washed by packed tower with the content of $\mathrm{NH}_{3}, \mathrm{CO}$ and $\mathrm{CO}_{2}$ within $10 \mathrm{ppm}$ and the pressure controlled within $3.1 \mathrm{MPa}$. The processed gas after PSA was used as the feed gas. The second was that $\mathrm{NH}_{3}$ of purge gas in liquid ammonia tank was washed by double tower circulation method to produce $10 \%$ ammonium hydroxide which was used to desulfurize and remove nitrogen. And the residual gas was sent to analytical gas manifold after PSA.

There were two social and economic benefits. The first was that $\mathrm{H}_{2}$ and $\mathrm{NH}_{3}$ in purge gas could be recycled at the extreme, and the emission of purge gas was reduced to the environment to minimize the environment pollution. The second was that the quantity of $10 \%$ ammonium hydroxide recycled could be up to $17088 \mathrm{t} / \mathrm{a}$ with increasing benefits 1.7 million RMB a year $(10 \%$ ammonia hydroxide calculated at $100 \mathrm{RMB} / \mathrm{t}$ ), amounting to 5.47 million RMB.

\section{MAIN TECHNICAL INNOVATIONS}

\section{A. Energy Conservation}

- Reciprocating compressor driven by steam turbine could save energy more than $30 \%$ than that of driven by electricity. The cost of per ton of ammonia was less than similar scale ammonia using electrically driven reciprocating machine manufacturers about 300 RMB.

- Feed gas was the 3.2MPamethanol purge gas, which was directly access to the PSA, without gas compression process saving energy.

- The pressure in the equipment was $16 \mathrm{MPato}$ save a lot of energy.

- The system with methanol purge gas deflation to synthesize ammonia had low energy consumption. A series of innovative technologies and energy-saving measures were used in the project, and there was about $13.99 \mathrm{Gt} / \mathrm{t}$ of comprehensive energy consumption lower than the existing ammonia synthesis equipment with coal and coke as the raw material. There was energy consumption about $13.99 \mathrm{GJ} / \mathrm{t} \times$ $10^{5} \mathrm{t} / \mathrm{a}$, equivalent to standard coal of about $47,700 \mathrm{t} / \mathrm{a}$.

\section{B. Cyclic Utilization}

- The hydrogen and nitrogen extraction equipment were used for ammonia synthesis purge gas and gas in storage tank to make $\mathrm{H}_{2}$ return back to PSA for cyclic utilization, which could increase the production of ammonia synthesis, and the residual gas was used to produce methanol to realize the zero discharge of ammonia synthesis purge gas. $\mathrm{NH}_{3}$ was recycled to produce ammonium hydroxide which was used as the raw material to desulfurize and remove nitrogen in thermal power plant. It was a new bright technology spot to the project of purge gas cyclic utilization.

- The cyclic utilization of pressure swing absorbed and desorbed gas. After the hydrogen extraction of methanol under PSA, it was needed to make the absorbent recycled. The amount of desorbed gas was $12275 \mathrm{Nm}^{3} / \mathrm{h}$, whose calorific value was equivalent to that of methanol purge gas, which could be used as the raw material of coke oven gas or methanol. The raw material gas of methanol could be swapped out to use the desorbed gas circularly without any synthetic ammonia emission.

\section{REFERENCES}

[1] Lihong Chao, ZhouyunHui, Zhao Bin, etc.Equipment and Technology of Liquid Ammonia Production with Coke Oven Gas and Methanol Purge gas[P]. Chinese .CN201210270687.1,2012-11-7.

[2] Xuqing Ben, Gaojian Kang. PSA Hydrogen Purification and Its Influencing Factors[J]. Gansu Science and Technology, 2008, 24 (12): 32-33.

[3] Wang Hong, Wufeng Lin, Zhanghong Ying. Discussion and Analysis of Turbine Alternative Motor Drag Reciprocating Compressor[J]. Coal Chemical Industry, 2008, 134 (1): 35-37.

[4] Liyao Gang. Process Optimization of Pressure Swing Adsorption Hydrogen[J]. Fertilizer Design, 2009, 47(3): 36-38.

[5] Zhuhong Li, ZhuJianHua, Chen Jin. Advances in Technology of Separation Concentrated Hydrogen From Hydrogen-containing Gas. Qingdao University of Science and Technology [J], 2004, 25(5): 421-425.

[6] DaixianYue, Liu Li. Process Comparison of Purification Ammonia Feed Gas [J]. Yunnan Chemical, 2008, 35 (5): 54-57. 